\title{
Hypoxia Does neither Stimulate Pulmonary Artery Endothelial Cell Proliferation in Mice and Rats with Pulmonary Hypertension and Vascular Remodeling nor in Human Pulmonary Artery Endothelial Cells
}

\author{
Lunyin Yu Charles A. Hales \\ Pulmonary and Critical Care Unit, Department of Medicine, Massachusetts General Hospital, Harvard Medical School, \\ Boston, Mass., USA
}

\section{Key Words}

Pulmonary artery endothelial cell $\cdot$ Proliferation $\cdot$ Hypoxia $\cdot$ Mice $\cdot$ Rats

\begin{abstract}
Background: Hypoxia results in pulmonary hypertension and vascular remodeling due to induction of pulmonary artery cell proliferation. Besides pulmonary artery smooth muscle cells, pulmonary artery endothelial cells (PAECs) are also involved in the development of pulmonary hypertension, but the effect of hypoxia on PAEC proliferation has not been completely understood. Methods: We investigated PAEC proliferation in mice and rats with hypoxia-induced pulmonary hypertension and vascular remodeling as well as in human PAECs under hypoxia. Results and Conclusion: We did not find significant PAEC proliferation in chronically hypoxic rats or mice. There was a slight decrease in proliferation in mice and rats with pulmonary hypertension and vascular remodeling. We also did not find significant human PAEC proliferation and cell cycle progression under different levels of oxygen (1, 2, 3, 5 and 10\%) for one day, although the same conditions of hypoxia induced significant proliferation and cell cycle progression in pulmonary artery smooth muscle cells and pulmonary artery fibroblasts. Exposure to hypoxia for 7 days also did not increase PAEC proliferation.
\end{abstract}

These results demonstrated that hypoxia alone is not a stimulus to PAEC proliferation in vivo and in vitro. The present study provides a novel role for PAECs in hypoxia-induced pulmonary hypertension and vascular remodeling.

Copyright $\odot 2011$ S. Karger AG, Basel

\section{Introduction}

Pulmonary hypertension is characterized by structural changes in the pulmonary vasculature involving increased wall thickness of pulmonary arterioles due to hypertrophy and/or hyperplasia of pulmonary artery smooth muscle cells (PASMCs) $[1,2]$. Besides PASMCs, pulmonary artery endothelial cells (PAECs) in the intima are also involved in the development of pulmonary hypertension. For example, proliferation of PAECs is observed in the plexiform lesion, a complex pathological vascular structure seen in the late stage of pulmonary hypertension [1]. In addition, dysfunction of PAECs has been observed in pulmonary hypertension in several studies [3-11] and investigators recently have shown that endothelial progenitor cells were beneficial in treatment of pulmonary hypertension [9, 12-18]. Therefore, PAECs have been suggested to play an important role in pulmonary hypertension and vascular remodeling.

\section{KARGER}

(C) 2011 S. Karger AG, Basel

Fax +41613061234 E-Mail karger@karger.ch www.karger.com www.karger.com/jvr
Dr. Lunyin Yu

Pulmonary and Critical Care Unit, Department of Medicine

Massachusetts General Hospital, Harvard Medical School

55 Fruit Street, Bulfinch-148, Boston, MA 02114 (USA)

Tel. +1 617726 5630, E-Mail lyu3@partners.org 
Hypoxia is often an important factor in the pathogenesis of pulmonary hypertension and pulmonary remodeling. Actual hypoxia causes pulmonary vasoconstriction, in turn chronic hypoxia results in vascular remodeling with pulmonary artery cell proliferation and hypertrophy $[1,2]$. The hypoxia model of pulmonary hypertension in rodents is the most common animal model widely used for pulmonary hypertension research $[1,19$ 28]. Because significant proliferation and hypertrophy of PASMCs has been observed in different animal models, the relationship between hypoxia and PASMC proliferation has been widely studied [21, 22, 29]. There is little published information about the effect of hypoxia on PAEC proliferation [29], although hypoxia affects endothelial physiology [30]. A few studies have been done on hypoxia and proliferation of pulmonary artery cells [29, 31,32 ], but the results were not consistent. Tucci et al. [31] investigated the effect of hypoxia on bovine PAECs and found a decrease in PAEC proliferation after 5 days of exposure to $0 \%$ oxygen and a decrease in DNA synthesis after exposure to $0 \% \mathrm{O}_{2}$ for 24 and $48 \mathrm{~h}$. There was an increase in cell cycle progression in the PAECs exposed to $3 \% \mathrm{O}_{2}$. Toby et al. [32] found that $1 \%$ oxygen significantly induced proliferation of human pulmonary micro vascular endothelial cells during 5 days of incubation. Therefore, the exact effect of hypoxia on PAEC proliferation is still poorly understood.

In order to better understand the influence of hypoxia on PAECs, we investigated PAEC proliferation by using a mouse and rat model of hypoxia-induced pulmonary hypertension and vascular remodeling. We also investigated proliferation and cell cycle progression of human PAECs in vitro. To compare the effect of hypoxia on other pulmonary artery cells, we investigated human PASMC and PAF proliferation at the same oxygen conditions. We hypothesized that hypoxia would be a stimulus to PAEC proliferation.

\section{Materials and Methods}

\section{In vivo Study}

Animals

Animal experiments were approved by the Subcommittee on Research Animal Care at Massachusetts General Hospital. Male C57BL/6 mice, 8-10 weeks old, were obtained from Jackson Laboratory (Bar Harbor, Me., USA). Male Sprague-Dawley rats, weighing 150-200 g, were obtained from Charles River Laboratories (Wilmington, Mass., USA). Mice and rats were placed in separate hypoxic chambers or exposed to normoxia for 2 weeks. Oxygen concentration was maintained at $10 \%$ by controlling the flow rates of compressed air and nitrogen [20-22]. Cage concentration of $\mathrm{O}_{2}$ was checked daily. The cages were opened once a day for 10 min to reduce $\mathrm{CO}_{2}$ concentration.

Hemodynamic Measurement

After 14 days in the hypoxia chamber, the animals were removed and anesthetized with ketamine $(80 \mathrm{mg} / \mathrm{kg})$ and diazapam $(5 \mathrm{mg} / \mathrm{kg})$ for measurement of pulmonary hemodynamics as we published previously [21,22]. Right ventricular peak systolic pressure for mice and mean pulmonary artery pressure for rats were measured. Subsequently the animals were sacrificed with 200 $\mathrm{mg} / \mathrm{kg}$ of intraperitoneal pentobarbital and used immediately for the determination of right ventricular hypertrophy, hematocrit and lung pathology.

Pathological Evaluation

Right ventricular hypertrophy was measured as the ratio of right ventricular weight to left ventricular plus septal weight [21, 22]. Pulmonary vascular remodeling was assessed by measuring percent wall thickness of the pulmonary arterioles. A computer imaging analysis system was applied for this measurement. Images of individual pulmonary arterioles were captured using a digital camera mounted on a light microscope and linked to a computer. Wall thickness was measured as described previously $[21,22]$.

PAEC Proliferation Analysis

Ki67 expression was used to evaluate PAEC proliferation in vivo. Anti-Ki67 antibody (rabbit polyclonal, dilution 1:25) was obtained from Abcam Inc. (Cambridge, Mass., USA). Immunohistochemical staining of paraffin sections of lung tissue was performed with a labeled (strept)avidin-biotin detection kit (Histostain-plus kit; Zymed Laboratory Inc., South San Francisco, Calif., USA) following the manufacturer's protocol [21, 22]. The slides were counterstained with hematoxylin. Control slides were treated identically, but without the primary antibody. The identification of positive cellular status was determined by a blinded pathologist using Ki67 nuclear staining resulting in brown color. The percentage of Ki67-positive cells was estimated by calculating the ratio of Ki67-expressing cell nuclei to the total number of cell nuclei in the wall of terminal pulmonary bronchial arterioles and in intra-acinous arterioles. At least 10 vessels from each slide were counted and 10 animals for each group were used in this study.

\section{In vitro Study}

Cells

Human pulmonary artery endothelial cells (HPAECs; cat. No. CC-2530) and endothelial growth medium, human pulmonary artery smooth muscle cells (HPASMCs; cat. No. CC-2581) and smooth muscle growth medium (SmGM-2) were obtained from Lonza Inc. (Walkersville, Md., USA). Human pulmonary artery fibroblasts (HPAFs; cat. No. 3120) and fibroblast medium (cat. No. 2301) were obtained from ScienCell Research Laboratories (Carlsbad, Calif., USA). The PAECs, PASMCs and PAFs in passage 4 and 5 were used in this study.

Hypoxia and Hypoxia Chamber

Gases $\left(1,2,3,5\right.$ and $10 \% \mathrm{O}_{2}$ in $5 \% \mathrm{CO}_{2}$ balance nitrogen) in cylinders were obtained from Airgas East (Cambridge, Mass., USA). Hypoxia chamber (modular incubator chamber) was obtained from Billups-Rothenberg Inc. (Del Mar, Calif., USA). Cells 
grown in $21 \% \mathrm{O}_{2}$ with $5 \% \mathrm{CO}_{2}$ in regular cell incubator were used for normoxia controls. The hypoxia chamber was placed in a regular $\mathrm{CO}_{2}$ incubator maintained at $37^{\circ} \mathrm{C}$. The concentration of oxygen in the chamber was monitored with an oxygen analyzer, showing stable oxygen concentration as indicated on the cylinders.

\section{Cell Culture and Hypoxia Exposure}

HPAECs, HPASMCs and HPAFs were separately plated in 12well cell culture plates at $1 \times 10^{4}$ cells per well, allowed to grow for $24 \mathrm{~h}$, and growth arrested with serum-free media for another $24 \mathrm{~h}$ in a regular $\mathrm{CO}_{2}$ incubator. Following growth arrest, the media were then changed to standard media and then the cells were placed into the hypoxia chamber. After exposure to hypoxia for $24 \mathrm{~h}$, the cells were harvested for cell proliferation assay and cell cycle analysis.

\section{Cell Proliferation Assay}

We assayed cell proliferation by using direct cell count and 5-bromo-2'deoxyuridine (BrdU) incorporation assay. Direct cell count followed growth of the human PAECs in regular media for $24 \mathrm{~h}$ and growth arrest with serum-free media for another $24 \mathrm{~h}$, the cell numbers were assessed by directly counting the number of cells with a hemocytometer under a light microscope. Percent growth of the cells was calculated as: (cell number in treatment group/cell number in control group) $\times 100$ [16]. For BrdU incorporation assay, human PAECs were seeded on chamber slides. After growth in regular media for $24 \mathrm{~h}$ and growth arrest with serum-free media for another $24 \mathrm{~h}$, the media was changed to regular media and BrdU (10 ng/ml; Sigma; St. Louis, Mo., USA) was added to the media. Then the cells were incubated in the hypoxia chamber for $24 \mathrm{~h}$. After hypoxia exposure, the cells were washed, fixated and then stained with the BrdU antibody by using a BrdU staining kit (Invitrogen, Carlsbad, Calif., USA) following the manufacturer's instruction. BrdU-positive nuclei number and total nucleated cells were counted. Cell proliferation capacity was shown as a percentage of BrdU-positive nuclei over total nucleated cells.

\section{Cell Cycle Analysis}

Cell cycle was analyzed using flow cytometry. After harvesting the cells, pellets of the cells were obtained by centrifugation. Following removal of the media, the pellets were resuspended with $10 \mu \mathrm{l}$ of PBS, $1 \mathrm{ml}$ of $70 \%$ ethanol was added followed by centrifuging and washing with cold PBS. The cells were then resuspended in $20 \mu \mathrm{g} / \mathrm{ml}$ of propidium iodide/PBS with $1 \mathrm{mg} / \mathrm{ml}$ of RNase. After incubating for $15 \mathrm{~min}$ at room temperature, the samples were run on 7 Laser SORP BD LSR II. Data were collected with DIVA software on LSR II and analyzed with FlowJo v8.8.6.

\section{Cell Migration Assay}

The wound healing assay was used to analyze cell migration following previously published methods $[33,34]$. Briefly, HPAECs were seeded at $4 \times 10^{6}$ cells/well on 12 -well cell culture plates to allow the cells to grow confluent. On the second day, 3 straight scratches for each well were made with $200-\mu l$ pipette tip. Wells were then rinsed with PBS, replaced with regular media and then incubated under $2 \%$ oxygen for $24 \mathrm{~h}$. Pictures of the scratched wounds were taken at 0 and $24 \mathrm{~h}$. Migration was determined by measurement of the wound width of the scratched gaps.

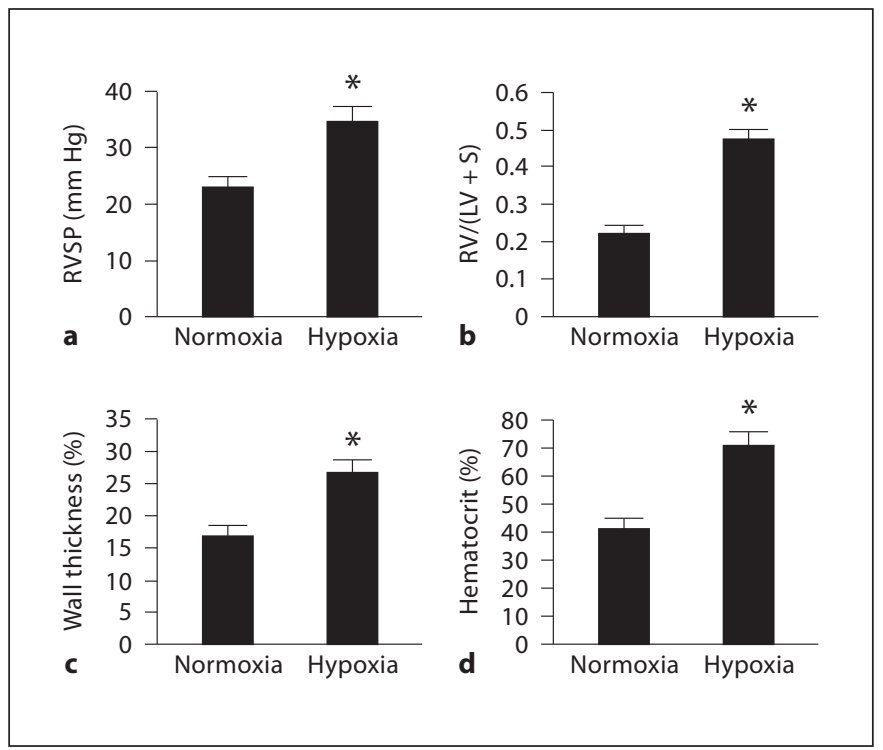

Fig. 1. Hypoxia induced pulmonary hypertension and vascular remodeling in mice. After exposure of mice to $10 \%$ oxygen or room air for 2 weeks, the animals were removed from hypoxia chamber for measurements. Right ventricular systolic pressure (RVSP) (a), right ventricular hypertrophy as shown by the weight ratio of right ventricle to left ventricle plus septum $[\mathrm{RV} /(\mathrm{LV}+\mathrm{S})]$ (b), percent wall thickness of pulmonary arterioles (c) and hematocrit $(\mathbf{d}) .{ }^{*} \mathrm{p}<0.05$ as compared with normoxia group. $\mathrm{n}=10$ for each group.

\section{Statistical Analysis}

Statistics were performed using the computer program Statview (SAS Institute Inc., Cary, N.C., USA) with factorial ANOVA. If ANOVA was significant, multiple comparisons were made among groups using the Fisher protected least significant difference test. All values were expressed as the mean \pm SEM. Significance was set at $\mathrm{p}<0.05$.

\section{Results}

\section{Hypoxia Induced Significant Pulmonary \\ Hypertension and Vascular Remodeling in Mice}

After exposure to hypoxia for 2 weeks, the mice developed pulmonary hypertension and vascular remodeling, showing a significant increase in right ventricular systolic pressure, ratio of right ventricular weight to left ventricular plus septal weight and wall thickness of pulmonary arterioles as well as in hematocrit, as compared with normoxia control animals (fig. 1). The results were consistent with the data that we published previously [2022]. 
Fig. 2. Effect of hypoxia on PAEC proliferation in mice. After exposure to $10 \%$ oxygen for 2 weeks, the animals were removed from hypoxia for measurements and the lungs were harvested. The lung tissues fixed in $10 \%$ formalin were sectioned for immunohistochemical stain with Ki67. The number of Ki67-positive and Ki67negative endothelial cells was counted and the percent Ki67-positive PAECs was calculated. a, b Representative micrographs, showing that Ki67-positive cells were stained in brown marked by red arrows and the negative cells in blue marked by dark arrows. a Representative longitudinal section of a pulmonary arteriole. The pink lines in the insets show the structure of the tissue section. $\mathrm{E}=$ Epithelium of bronchiole; $\mathrm{I}=$ intima; $\mathrm{M}=$ media; $\mathrm{A}=$ advantitia of pulmonary arteriole. One positive stained PAEC is labeled with a dark arrow plus an asterisk in the lower left inset. b Representative cross-section of a pulmonary arteriole. c Quantitative data (left) and representative micrographs (right) from normoxia $(\mathrm{N})$ and hypoxia $(\mathrm{H}) . \mathrm{n}=$ 10 mice for each group.

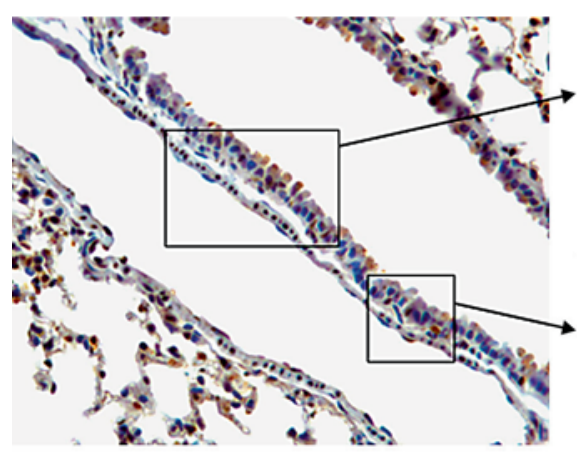

a
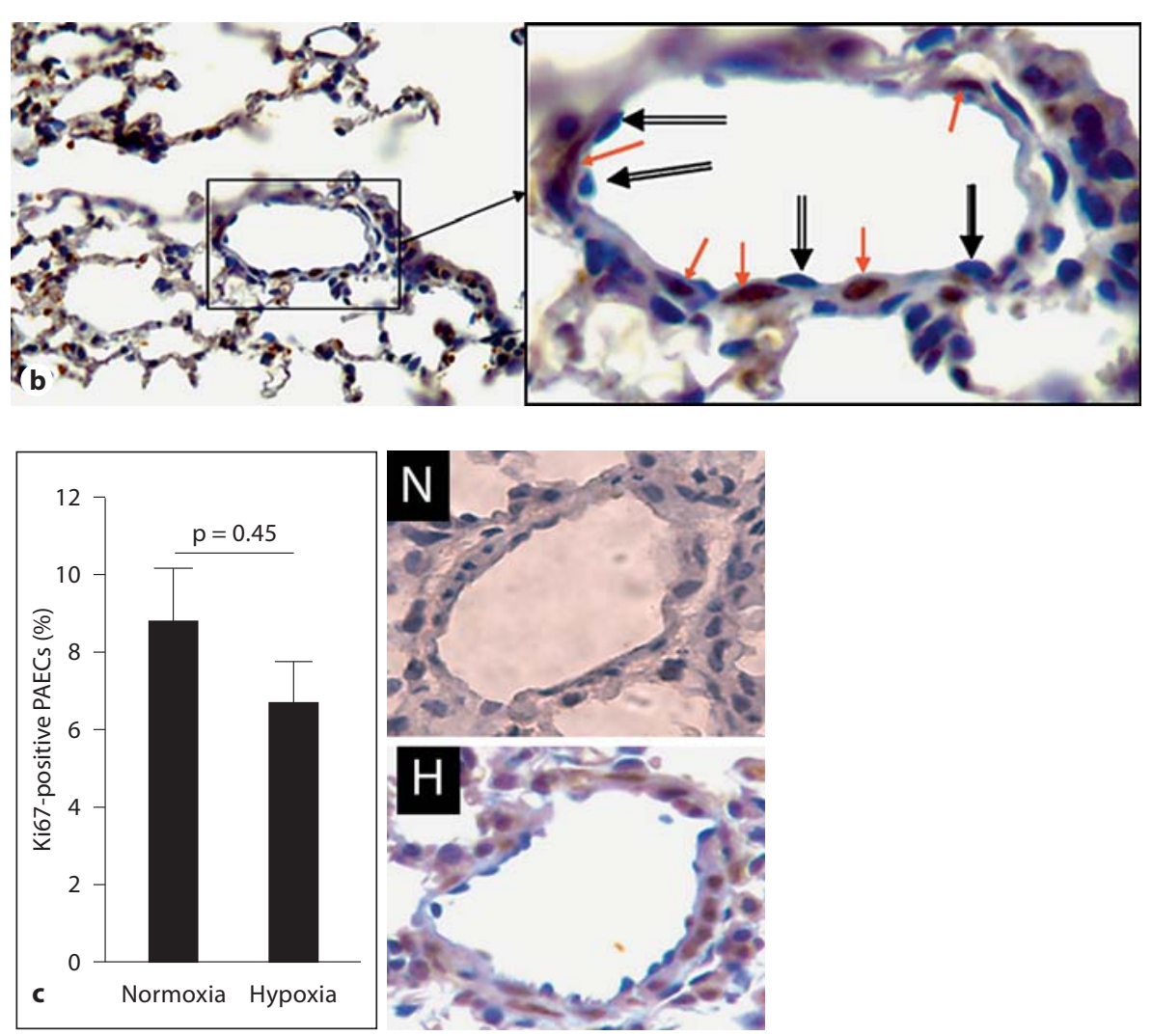

Hypoxia Did Not Increase PAEC Proliferation in Pulmonary Artery in Mice with Pulmonary Hypertension and Vascular Remodeling

After pulmonary hypertension and vascular remodeling were confirmed, we investigated cell proliferation in the pulmonary arterioles using immunohistochemistry with the cell proliferation marker Ki67. Successful staining of endothelial cells with Ki67 antibody was obtained, which showed Ki67-positive cells with a brown color in the nucleus compared to the negative cells in blue. The PAECs 


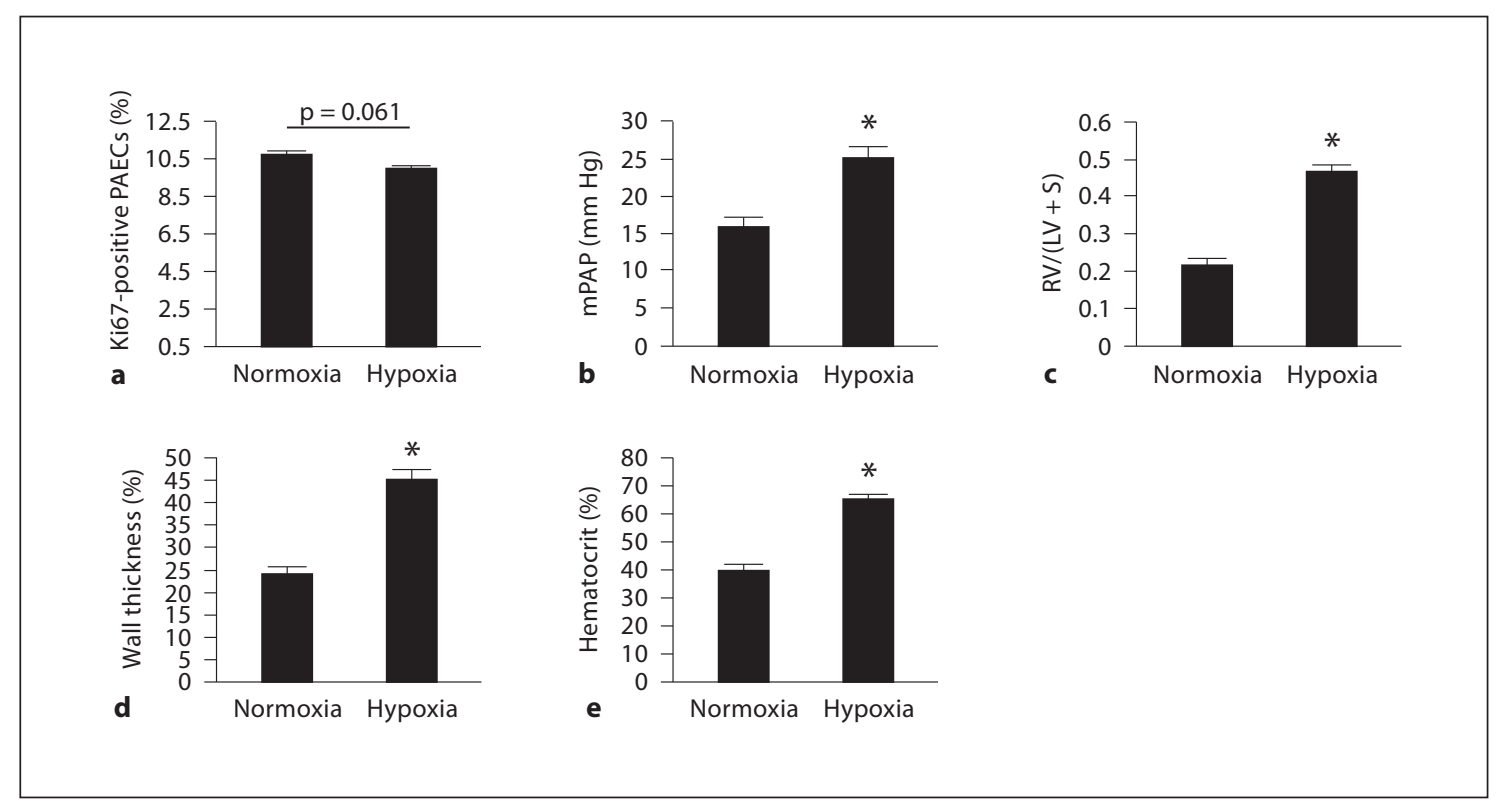

Fig. 3. Effect of hypoxia on PAEC proliferation in rats. After exposure of the rats to $10 \%$ oxygen for 2 weeks, they were removed from the hypoxia chamber for measurements. The lung tissues fixed in $10 \%$ formalin were sectioned for immunohistochemical stain with Ki67. a Ki67 index, showing the percentage of Ki67- positive PAECs over total counted PAECs. Mean pulmonary artery pressure (mPAP) (b), ratio of right ventricular weight to left ventricular plus septal weight $[\mathrm{RV} /(\mathrm{LV}+\mathrm{S})](\mathbf{c})$, percent wall thickness of pulmonary arterioles (d) and hematocrit (e). ${ }^{*} \mathrm{p}<0.05$ as compared with normoxia group. $\mathrm{n}=10$ rats for each group. displayed the distinguishing long spindle morphology lining on the very thin inner layer in the lumen of pulmonary arterioles (fig. 2a, b). We counted the number of both Ki67-positive and Ki67-negative endothelial cells in the inner layer and found no increase in the number of Ki67positive PAECs in pulmonary arterioles in the mice with pulmonary hypertension and vascular remodeling as compared with the normoxia control animals (fig. 2c). Consistent with our previous studies [21, 22], we found a significant increase in PASMCs in the medial layer of the pulmonary arterioles (data not shown). These data provided convincing histopathological evidence that PAEC growth was not stimulated in mice in vivo under hypoxia.

\section{Hypoxia Did Not Increase PAEC Proliferation}

in Pulmonary Artery in Rats with Pulmonary

Hypertension and Vascular Remodeling

In order to further demonstrate the finding in mice, we used a rat model of hypoxia-induced pulmonary hypertension and vascular remodeling. Interestingly, we also did not observe an increase in PAEC proliferation in the rats with hypoxia-induced pulmonary hypertension and vascular remodeling (fig. 3a), although the rats developed significant pulmonary hypertension and vascu- lar remodeling, with a significantly increased mean pulmonary pressure (fig. 3b), increased right ventricular hypertrophy (fig. 3c), increased wall thickness of pulmonary arterioles (fig. 3d) as well as an increase in hematocrit (fig. 3e) as compared with normoxia control animals. Once again, a smaller number of Ki67-positive cells was observed in the hypoxic animals as we observed in mice (fig. 3a), although the difference was not significant.

\section{Hypoxia Did Not Stimulate Proliferation and Cell \\ Cycle Progression of Human PAECs in vitro}

In order to extend upon the findings from animals, we conducted an in vitro study to investigate cell proliferation and cell cycle progression in PAECs. We used HPAECs and different concentrations of oxygen $(1,2,3$, 5 and $10 \%$ ) and used $21 \%$ oxygen of room air as control. We placed HPAECs in hypoxia chamber for $24 \mathrm{~h}$ and then harvested the cells for proliferation assay and cell cycle analysis. The proliferation of HPAECs was not stimulated under any of the concentrations of hypoxia by direct cell count (fig. 4a) and by BrdU incorporation assay (fig. 4b). Hypoxia actually slightly decreased the PAEC growth although the change was not significant. Subsequently, we analyzed the cell cycle using flow cytometry 

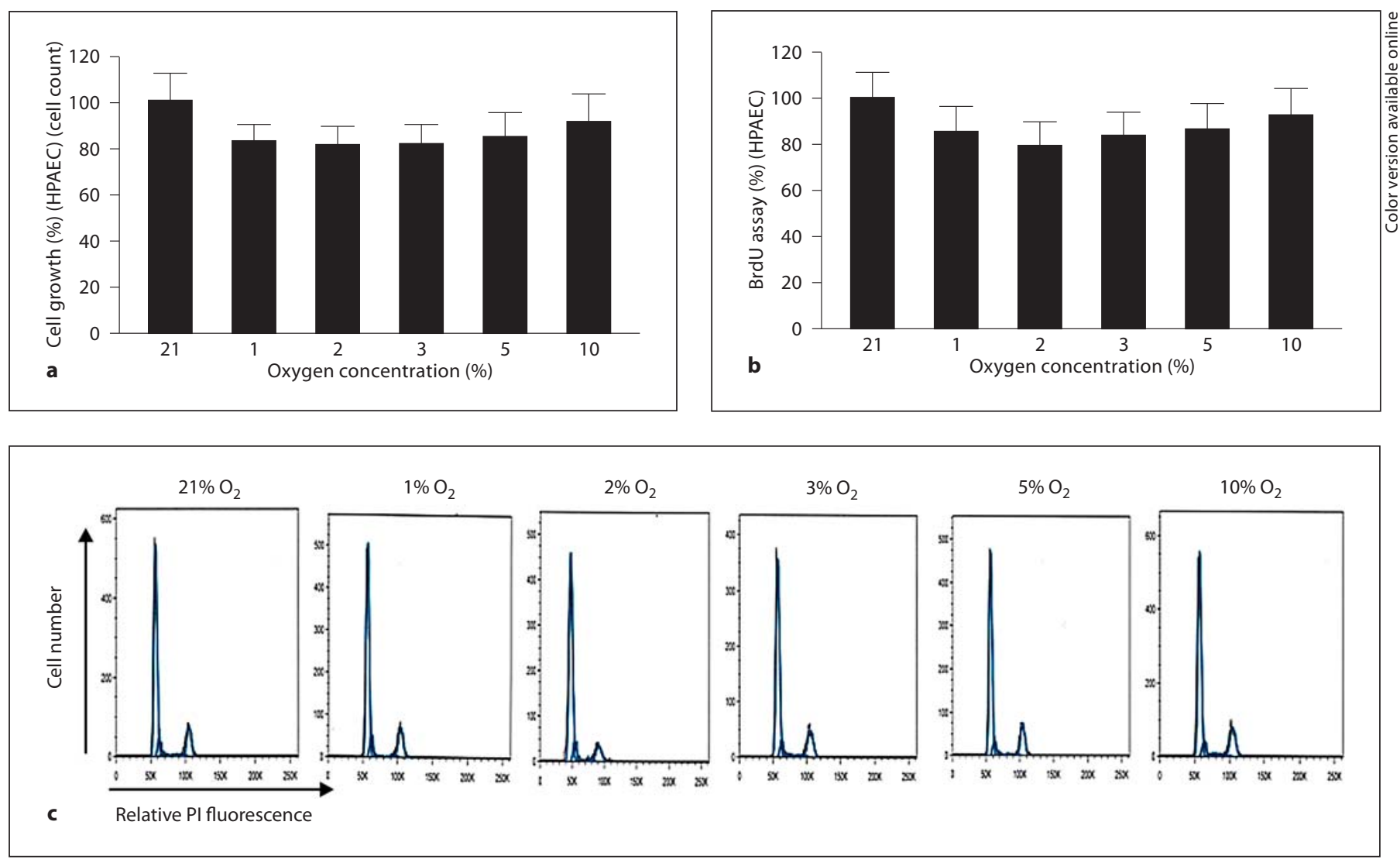

Fig. 4. Effect of hypoxia on human PAEC proliferation and cell cycle progression. Human PAECs were cultured in different levels of oxygen for $24 \mathrm{~h}$ and harvested for cell proliferation and for cell cycle analysis. Direct cell count for cell proliferation assay (a) and BrdU incorporation cell proliferation assay (b). The results were expressed as relative cell growth in percentage, which was compared with the $21 \%$ oxygen control group. We set the $21 \%$

and found consistent results with proliferation data, showing a decrease in the ratio of S plus G2/M phase and a slight increase in the ratio of G0/G1 phase (table 1; fig. 4c). These results indicated that hypoxia was not a stimulus to HPAEC proliferation and cell cycle progression.

\section{Hypoxia Increased Proliferation and Cell Cycle}

Progression of PASMCs and PAFs

To verify the hypoxia condition used for PAECs, we simultaneously cultured PAECs, PASMCs and PAFs in the hypoxia chamber by using the same procedures as above. We found that the growth of PASMCs and PAFs was significantly increased at different levels of oxygen concentration and the cell cycle progression was also stimulated significantly (fig. 5a, b; tables 2, 3). oxygen control group as 100 . No significant difference was observed between the groups. $\mathrm{n}=9$ for each group. $\mathbf{c}$ Representative flow cytometry graphs for cell cycle analysis (quantitative data shown in table 1). There are two plots superimposed for each oxygen percentage. The one in black (color in online version only) is the actual DNA histogram and the other in blue is the DNA model fit.

\section{Long-Term Hypoxia Exposure Did Not Increase HPAEC Growth}

In order to investigate if chronic hypoxia affected PAECs differently from acute hypoxia in vitro, we cultured HPAECs under 2\% oxygen for 7 days and found that long-term exposure to hypoxia also did not increase HPAEC proliferation (fig. 6).

\section{Hypoxia Did Not Stimulate PAEC Migration in vitro}

We additionally investigated the effect of hypoxia on migration of HPAECs using a wound healing assay. We found that hypoxia significantly inhibited HPAEC migration under hypoxia as compared with normoxia control (fig. 7). 


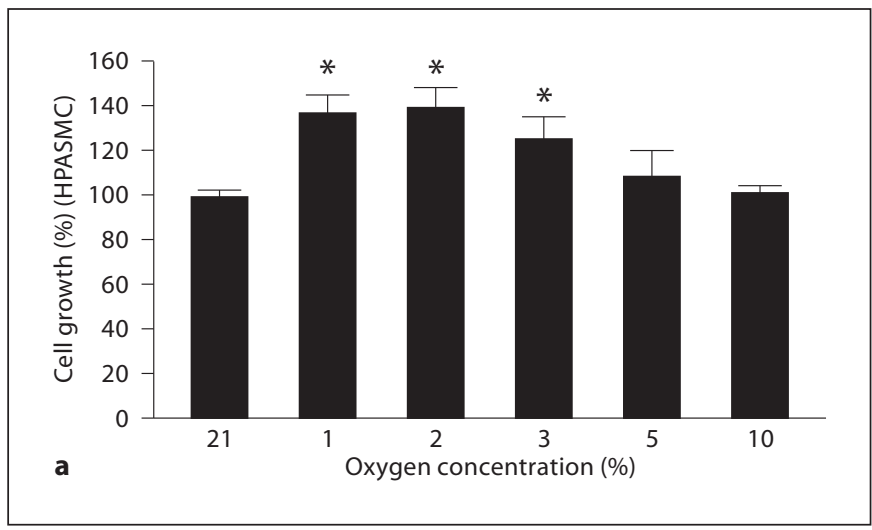

Fig. 5. Effect of hypoxia on PASMC and PAF proliferation. PASMCs and PAFs were cultured in different levels of oxygen for $24 \mathrm{~h}$ and then harvested for cell count for growth assay. The results were expressed as relative cell growth in percentage, which was

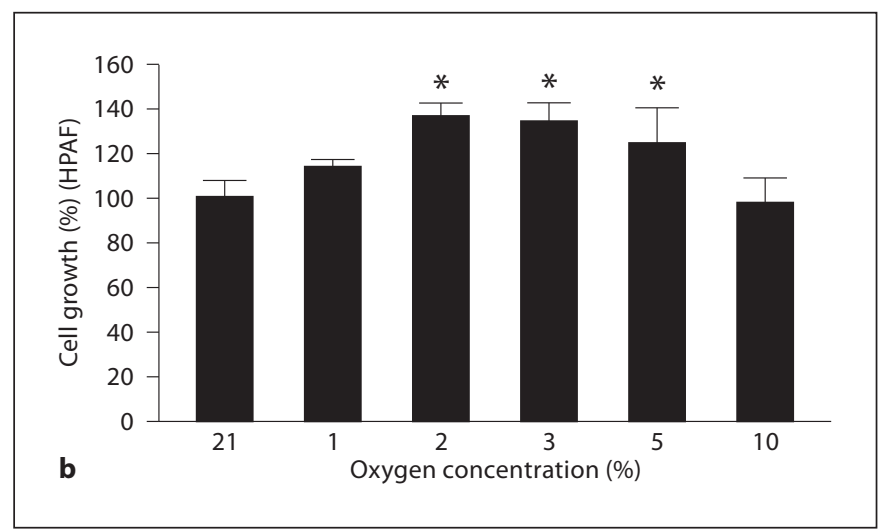

compared with the room air control group. We set the room air control group as 100. PASMCs (a) and PAFs (b). $n=9$ for each group. Quantitative data on cell cycle analysis are shown in tables 2 and 3.

Table 1. Effect of hypoxia on cell cycle progression of HPAECs

\begin{tabular}{|c|c|c|c|c|c|c|}
\hline \multirow[t]{2}{*}{ Cell phase } & \multicolumn{6}{|c|}{ Oxygen concentration, $\%$} \\
\hline & 21 & 1 & 2 & 3 & 5 & 10 \\
\hline G0/G1 & $68.7 \pm 3.1$ & $68.1 \pm 1.9$ & $75.8 \pm 3.5$ & $73.1 \pm 4.0$ & $71.7 \pm 2.7$ & $69.2 \pm 3.2$ \\
\hline $\mathrm{S}$ & $15.6 \pm 1.2$ & $10.4 \pm 1.3^{*}$ & $10.0 \pm 1.4^{*}$ & $9.8 \pm 0.9^{*}$ & $9.2 \pm 3.1^{*}$ & $10.1 \pm 1.9^{*}$ \\
\hline $\mathrm{G} 2 / \mathrm{M}$ & $14.6 \pm 1.3$ & $17.3 \pm 2.1$ & $13.5 \pm 1.1$ & $17.0 \pm 2.5$ & $17.8 \pm 2.0$ & $18.1 \pm 0.9$ \\
\hline
\end{tabular}

${ }^{*} \mathrm{p}<0.05$ as compared with $21 \% \mathrm{O}_{2} . \mathrm{n}=5$ for each group.

Table 2. Effect of hypoxia on cell cycle progression of HPASMCs

\begin{tabular}{lllllll}
\hline Cell phase & \multicolumn{2}{l}{ Oxygen concentration, \% } & & & \\
\cline { 2 - 6 } & 21 & $1^{*}$ & $2^{*}$ & $3^{*}$ & 5 & 10 \\
\hline G0/G1 & $57.2 \pm 1.7$ & $47.1 \pm 2.0$ & $46.6 \pm 2.3$ & $48.5 \pm 4.1$ & $52.1 \pm 2.7$ & $57.9 \pm 3.2$ \\
S & $30.1 \pm 2.0$ & $35.6 \pm 3.7$ & $35.8 \pm 1.8$ & $34.9 \pm 2.9$ & $32.4 \pm 3.1$ & $30.8 \pm 1.9$ \\
G2/M & $12.2 \pm 1.4$ & $15.8 \pm 0.8$ & $16.3 \pm 2.4$ & $15.4 \pm 0.7$ & $13.0 \pm 2.0$ & $12.1 \pm 0.9$ \\
\hline
\end{tabular}

${ }^{*} \mathrm{p}<0.05$ as compared with $21 \% \mathrm{O}_{2} . \mathrm{n}=5$ for each group.

Table 3. Effect of hypoxia on cell cycle progression of HPAFs

\begin{tabular}{|c|c|c|c|c|c|c|}
\hline \multirow[t]{2}{*}{ Cell phase } & \multicolumn{6}{|c|}{ Oxygen concentration, \% } \\
\hline & 21 & 1 & $2^{*}$ & $3^{*}$ & $5^{*}$ & 10 \\
\hline G0/G1 & $76.9 \pm 3.0$ & $71.1 \pm 2.5$ & $59.5 \pm 2.3$ & $52.3 \pm 1.8$ & $62.2 \pm 0.7$ & $78.0 \pm 4.6$ \\
\hline $\mathrm{S}$ & $12.1 \pm 0.7$ & $15.0 \pm 3.1$ & $25.0 \pm 2.0$ & $27.0 \pm 3.0$ & $15.5 \pm 1.7$ & $10.8 \pm 3.1$ \\
\hline $\mathrm{G} 2 / \mathrm{M}$ & $5.1 \pm 1.0$ & $9.4 \pm 1.2$ & $8.1 \pm 1.3$ & $17.1 \pm 1.8$ & $10.3 \pm 3.0$ & $9.9 \pm 1.0$ \\
\hline
\end{tabular}

${ }^{*} \mathrm{p}<0.05$ as compared with $21 \% \mathrm{O}_{2} . \mathrm{n}=5$ for each group. 


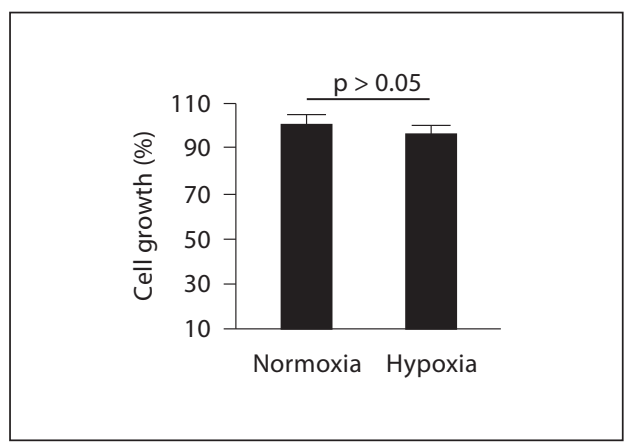

Fig. 6. Effect of chronic exposure to hypoxia on in vitro human PAEC proliferation in vitro. PAECS were cultured in $2 \%$ oxygen for 7 days and harvested for cell count to assay cell proliferation. The results were expressed as relative cell growth in percentage, which was compared with the normoxia group. We set the normoxia group as 100. $\mathrm{n}=9$ for each group.

\section{Discussion}

In this study, we found that PAECs did not significantly proliferate in pulmonary arterioles (fig. 2) in mice with hypoxia-induced pulmonary hypertension and vascular remodeling (fig. 1). We found similar results in rats with hypoxia-induced pulmonary hypertension and vascular remodeling, showing no significant PAEC proliferation (fig. 3). Hypoxia did not stimulate human PAEC growth in vitro (fig. $4 \mathrm{a}, \mathrm{b}$ ) and did not promote cell cycle progression in the PAECs (table 1; fig. 3c), although significant proliferation and cell cycle progression of PASMCs and PAFs were observed in the same hypoxic condition (table 2, 3; fig. 5a, b). Long-term exposure to hypoxia also did not increase growth activity of PAECs (fig. 6) and PAEC migration was not stimulated under hypoxia (fig. 7).

Vascular remodeling of pulmonary arterioles is a characteristic morphological change in pulmonary hypertension, which results mainly from proliferation of pulmonary arterial structural cells, including smooth muscle cells, endothelial cells and fibroblasts through complicated mechanisms $[1,2,35]$. In a plexiform lesion of pulmonary hypertension, deregulated growth of endothelial cells has been observed [36-39]. In an animal model of pulmonary hypertension induced by hypoxia plus vascular endothelial growth factor receptors 1 and 2 inhibitor SU5416, significant proliferation of endothelial cells in pulmonary arterioles was observed [40, 41]. However, there has been no convincing histopathological evidence showing PAEC proliferation in other animal models of pulmonary hypertension, especially hypoxia-induced pulmonary hyperten-
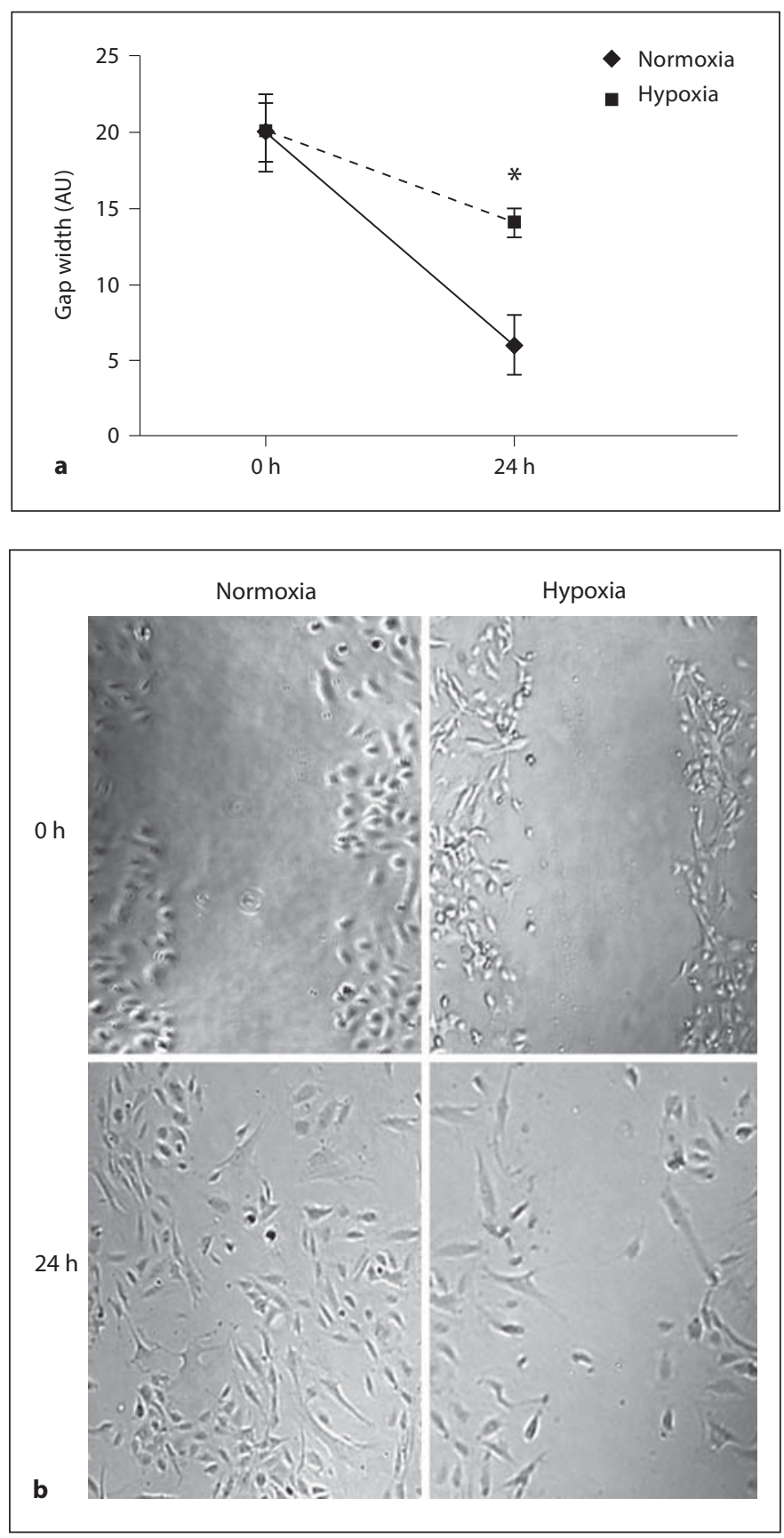

Fig. 7. Effect of hypoxia on human PAEC migration. After growth in regular media for $24 \mathrm{~h}$ and growth arrest of the PAECs for another $24 \mathrm{~h}$, we made scratches by using a pipette tip. The cells were then placed in $2 \%$ oxygen for $24 \mathrm{~h}$. Quantitative data (a) on the width of scratched gaps, showing PAEC migration, and representative pictures taken at zero and $24 \mathrm{~h}(\mathbf{b}) .{ }^{*} \mathrm{p}<0.05$ as compared with normoxia. The results were from 3 separate experiments. $\mathrm{n}=9$ for each group. 
sion and vascular remodeling. Therefore, the effect of hypoxia on PAEC proliferation in vivo has not been clearly delineated. In this study, we investigated PAEC proliferation in vivo using the popular animal model of hypoxiainduced pulmonary hypertension and vascular remodeling in mice and rats. We first investigated the mouse model and found that there was no significant increase in PAEC proliferation in the intima. In fact there was a slight although insignificant decrease in a proliferation marker in the PAECs in mice with pulmonary hypertension and vascular remodeling as compared with normoxic animals, even though the mice developed significant pulmonary hypertension and vascular remodeling after exposure to hypoxia for 2 weeks. We found significantly increased numbers of PASMCs in the medial wall of the hypoxic pulmonary arterioles as we reported previously [21, 22]. To further extend the results in mice, we used a rat model and obtained similar results to the mouse model of pulmonary hypertension, showing no increase in PAEC proliferation in the hypoxic rats with pulmonary hypertension and vascular remodeling. The results from this study firmly demonstrated that there was no PAEC proliferation in a hypoxic model of pulmonary hypertension and vascular remodeling in mice and rats. Interestingly, a recent report from Teng et al. [42] showed a decrease in PAEC proliferation in a lamb model of persistent pulmonary hypertension of the newborn induced by ductus arteriosus ligation. Our study indicates that hypoxia alone is not a stimulus to PAEC proliferation in vivo. Therefore, the expanded PAECs in plexiform lesion in patients with pulmonary hypertension were either altered in their response to hypoxia or their proliferation was not initiated by hypoxia, but by other injurious endothelial factors.

Since we did not observe PAEC proliferation in animals with hypoxia-induced pulmonary hypertension and vascular remodeling, we performed an in vitro study to further confirm our findings. We investigated the effect of different levels of oxygen on HPAECs and compared them with HPASMCs and HPAFs using the same conditions. We found that hypoxia did not increase but slightly inhibited the PAEC growth under 1, 2, 3, 5 and $10 \%$ oxygen, although significant proliferation of the PASMCs and the PAFs was observed under the same hypoxia levels. Tucci et al. [31] investigated bovine PAEC proliferation in response to hypoxia. They found that the proliferation of bovine PAECs was significantly decreased during 5 days exposure to $0 \%$ oxygen, either in the cells previously growing in 21 or $3 \% \mathrm{O}_{2}$. They also found that a slight decrease in BrdU incorporation in the PAECs exposed to $0 \% \mathrm{O}_{2}$ for either 24 or $48 \mathrm{~h}$. Recently,
Toby et al. [32] found that $1 \%$ oxygen significantly induced proliferation of human pulmonary micro vessel endothelial cells during 5 days of incubation. Masri et al. [43] reported a significant increase in proliferation in the PAECs isolated from idiopathic pulmonary artery hypertension during 3 days incubation under normoxia as compared with the PAECs from normal controls. Unfortunately, they did not show the effect of hypoxia on the cells. Fantozzi et al. [44] investigated the mechanism by which hypoxia induced PAEC proliferation. They found that activating protein-1 played an important role in a signaling pathway that mediates human PAEC proliferation, but they did not directly show the effect of hypoxia on the PAEC proliferation.

To define the effect of long-term exposure to hypoxia on PAEC proliferation, we cultured HPAECs in $2 \%$ oxygen for 7 days. Consistent with the data we obtained from $24 \mathrm{~h}$ of exposure to hypoxia, we did not observe increased growth of the HPAECs. Solodushko et al. [45] reported on the influence of hypoxia on pulmonary microvascular endothelial cells (PMVECs) in their study on hypoxia and pulmonary endothelial integrity. They used three different cell lines of PMVECs from human and rat and found that $5 \%$ oxygen for 10 days decreased PMVEC proliferation in one cell line from human PMVECs and in one cell line from rat PMVECs, but no significant change in another primary human PMVEC cell line. There was also no increased growth of human and rat PMVECs during 10 days of exposure to hypoxia.

Since we observed that HPAEC proliferation was not stimulated under hypoxia, we wondered if cell cycle progression of the PAECs was affected similarly. To examine the change in cell cycle progression, we conducted flow cytometry to analyze the phases of cell cycle. We also investigated HPASMCs and HPAFs at the same time. Consistently, we found that hypoxia inhibited cell cycle progression in PAECs, but the same condition of hypoxia stimulated cell cycle progression of PASMCs and PAFs. The data showed that the G0/G1 phase was slightly increased and the $S$ phase was significantly decreased in the HPAECs exposed to different levels of hypoxia. Tucci et al. [31] reported that progression through G1 to S transition point and/or progression from $S$ to $\mathrm{G} 2 / \mathrm{M}$ was altered with an increased percent of bovine PAECs in S phrase during hypoxia. They found that a decrease in G0/G1 phase and increase in $S$ and G2/M phase in the bovine PAECs exposed to $3 \%$ oxygen, although they found that $0 \% \mathrm{O}_{2}$ decreased the bovine PAEC proliferation. However, we did not observe either a decrease in the G0/G1 phase or an increase in S and G2/M phase in HPAECs 
exposed to different levels of oxygen. Our data also demonstrated that hypoxia was not a stimulus to cell cycle progression of HPAECs.

Migration of pulmonary artery cells is involved in the pathogenesis of pulmonary hypertension, but PAEC migration under hypoxia has not been well studied. Some mechanisms on PAEC and lung endothelial cell migration have been investigated [46, 47], but those studies did not show the effect of hypoxia on PAECs. Phillips et al. [48] investigated the effect of hypoxia on bovine pulmonary microvessel endothelial cells and found that hypoxia stimulated formation of capillary network in the cells. However, they did not report the effect of hypoxia on the cell migration. In this study, we found that hypoxia exposure did not stimulate but inhibited HPAEC migration. Our results indicate that hypoxia also was not a stimulus to PAEC migration.

\section{Conclusion}

Our data from this study showed no significant PAEC proliferation in mice and rats with hypoxia-induced pulmonary hypertension and vascular remodeling, and also showed no significant proliferation and cell cycle progression of human PAECs under hypoxia in vitro. These results demonstrated that hypoxia alone is not a stimulus to PAEC proliferation, which provides new insight into the role of PAECs in hypoxia-induced pulmonary hypertension and vascular remodeling.

\section{Acknowledgements}

This work was supported by ATS/Pulmonary Hypertension Research Grant PH-08-010 (L.Y.) and NIH grant HL39150 (C.A.H.) as well as by the Susannah Wood Foundation.

\section{References}

1 Jeffery TK, Wanstall JC: Pulmonary vascular remodeling: a target for therapeutic intervention in pulmonary hypertension. Pharmacol Ther 2001;92:1-20.

2 Rabinovitch M: Pulmonary vascular remodeling in hypoxic pulmonary hypertension; in Yuan JX-J (ed): Hypoxic Pulmonary Vasoconstriction: Cellular and Molecular Mechanisms. Berlin, Kluwer Academic Publishers, 2004, pp 403-418.

-3 Diller GP, van Eijl S, Okonko DO, Howard LS, Ali O, Thum T, Wort SJ, Bédard E, Gibbs JS, Bauersachs J, Hobbs AJ, Wilkins MR, Gatzoulis MA, Wharton J: Circulating endothelial progenitor cells in patients with Eisenmenger syndrome and idiopathic pulmonary arterial hypertension. Circulation 2008;117:3020-3030

4 Marsboom G, Pokreisz P, Gheysens O, Vermeersch P, Gillijns H, Pellens M, Liu X, Collen D, Janssens S: Sustained endothelial progenitor cell dysfunction after chronic hypoxia-induced pulmonary hypertension. Stem Cells 2008;26:1017-1026.

5 Junhui Z, Xingxiang W, Guosheng F, Yunpeng S, Furong Z, Junzhu C: Reduced number and activity of circulating endothelial progenitor cells in patients with idiopathic pulmonary arterial hypertension. Respir Med 2008;102:1073-1079.

-6 Smadja DM, Gaussem P, Mauge L, IsraëlBiet D, Dignat-George F, Peyrard S, Agnoletti G, Vouhé PR, Bonnet D, Lévy M: Circulating endothelial cells: a new candidate biomarker of irreversible pulmonary hypertension secondary to congenital heart disease. Circulation 2009;119:374-381.
7 Morrell NW, Adnot S, Archer SL, Dupuis J, Jones PL, MacLean MR, McMurtry IF, Stenmark KR, Thistlethwaite PA, Weissmann N, Yuan JX, Weir EK: Cellular and molecular basis of pulmonary arterial hypertension. J Am Coll Cardiol 2009;54(suppl):S20-S31.

8 Xia L, Zhu JH, Qiu FY, Yang Y, Xie XD, Wang XX, Chen JZ, Fu GS: Senescent endothelial progenitor cells from dogs with pulmonary arterial hypertension: a before-after self-controlled study. J Physiol Sci 2009;59:429-437.

-9 Fadini GP, Avogaro A, Ferraccioli G, Agostini C: Endothelial progenitors in pulmonary hypertension: new pathophysiology and therapeutic implications. Eur Respir J 2010;35:418-425.

10 Smadja DM, Mauge L, Sanchez O, Silvestre JS, Guerin C, Godier A, Henno P, Gaussem P, Israël-Biet D: Distinct patterns of circulating endothelial cells in pulmonary hypertension. Eur Respir J 2010;36:1284-1293.

11 Tuder RM, Cool CD, Yeager M, Taraseviciene-Stewart L, Bull TM, Voelkel NF: The pathobiology of pulmonary hypertension. Endothelium. Clin Chest Med 2001;22:405418.

12 Takahashi M, Nakamura T, Toba T, Kajiwara N, Kato H, Shimizu Y: Transplantation of endothelial progenitor cells into the lung to alleviate pulmonary hypertension in dogs. Tissue Eng 2004;10:771-779.

13 Zhao YD, Courtman DW, Deng Y, Kugathasan L, Zhang Q, Stewart DJ: Rescue of monocrotaline-induced pulmonary arterial hypertension using bone marrow-derived endothelial-like progenitor cells: efficacy of combined cell and eNOS gene therapy in established disease. Circ Res 2005;96:442-450.
14 Zeng C, Wang X, Hu X, Chen J, Wang L: Autologous endothelial progenitor cells transplantation for the therapy of primary pulmonary hypertension. Med Hypotheses 2007; 68:1292-1295.

15 Wang XX, Zhang FR, Shang YP, Zhu JH, Xie XD, Tao QM, Zhu JH, Chen JZ: Transplantation of autologous endothelial progenitor cells may be beneficial in patients with idiopathic pulmonary arterial hypertension: a pilot randomized controlled trial. J Am Coll Cardiol 2007;49:1566-1571.

16 Ward MR, Stewart DJ, Kutryk MJ: Endothelial progenitor cell therapy for the treatment of coronary disease, acute MI, and pulmonary arterial hypertension: current perspectives. Catheter Cardiovasc Interv 2007;70: 983-998

17 Yip HK, Chang LT, Sun CK, Sheu JJ, Chiang $\mathrm{CH}$, Youssef AA, Lee FY, Wu CJ, Fu M: Autologous transplantation of bone marrowderived endothelial progenitor cells attenuates monocrotaline-induced pulmonary arterial hypertension in rats. Crit Care Med 2008;36:873-880.

18 Sun CK, Lee FY, Sheu JJ, Yuen CM, Chua S, Chung SY, Chai HT, Chen YT, Kao YH, Chang LT, Yip HK: Early combined treatment with cilostazol and bone marrow-derived endothelial progenitor cells markedly attenuates pulmonary arterial hypertension in rats. J Pharmacol Exp Ther 2009;330:718726.

19 Jeffery TK, Wanstall JC: Pulmonary vascular remodelling in hypoxic rats: effects of amlodipine, alone and with perindopril. Eur J Pharmacol 2001;416:123-131. 
20 Hales CA, Kradin RL, Brandstetter RD, Zhu YJ: Impariment of hypoxic pulmonary artery remodeling by heparin in mice. Am Rev Respir Dis 1983;128:747-751.

-21 Yu L, Quinn DA, Garg HG, Hales CA: Cyclin-dependent kinase inhibitor p27Kip1, but not p21WAF1/Cip1, is required for inhibition of hypoxia-induced pulmonary hypertension and remodeling by heparin in mice. Circ Res 2005;97:937-945.

-22 Yu L, Quinn DA, Garg HG, Hales CA: Deficiency of the NHE1 gene prevents hypoxiainduced pulmonary hypertension and vascular remodeling. Am J Respir Crit Care Med 2008;177:1276-1284.

23 Hassoun PM, Thompson BT, Steigman D, Hales CA: Effect of heparin and warfarin on chronic hypoxic pulmonary hypertension and vascular remodeling in the guinea pig. Am Rev Respi Dis 1989;139:763-768.

-24 Spence CR, Thompson BT, Janssens SP, Steigman DM, Hales CA: Effect of aerosol heparin on the development of hypoxic pulmonary hypertension in the guinea pig. Am Rev Respir Dis 1993;148:241.

25 Hassoun PM, Thompson BT, Hales CA: Partial reversal of hypoxic pulmonary hypertension by heparin. Am Rev Resp Dis 1992; 145:193-196.

-26 Joseph PAM, Garg HG, Thompson BT, Liu X, Hales CA: Influence of molecular weight, protein core and charge of native heparin fractions on pulmonary artery smooth muscle cells proliferation. Biochem Biophys Res Comm 1997;241:18-23.

-27 Al-Ansari E, Du HK, Yu L, Ochoa CD, Garg HG, Quinn DA, Hales CA: Low-molecularweight heparin inhibits hypoxic pulmonary hypertension and vascular remodeling in guinea pigs. Chest 2007;132:1898-1905.

28 Ochoa CD, Yu L, Al-Ansari E, Hales CA, Quinn DA: Thrombospondin-1 null mice are resistant to hypoxia-induced pulmonary hypertension. J Cardiothorac Surg 2010;5: 32.

-29 Pak O, Aldashev A, Welsh D, Peacock A: The effects of hypoxia on the cells of the pulmonary vasculature. Eur Respir J 2007;30:364372.

-30 Faller DV: Endothelial cell responses to hypoxic stress. Clin Exp Pharmacol Physio 1999;26:74-84.
1 Tucci M, Hammerman SI, Furfaro S, Saukonnen JJ, Conca TJ, Farber HW: Distinct effect of hypoxia on endothelial cell proliferation and cycling. Am J Physiol 1997; 272:C1700-C1708.

32 Toby IT, Chicoine LG, Cui H, Chen B, Nelin LD: Hypoxia-induced proliferation of human pulmonary microvascular endothelial cells depends on epidermal growth factor receptor tyrosine kinase activation. Am J Physiol Lung Cell Mol Physiol 2010;298: L600-L606.

33 James MF, Beauchamp RL, Manchanda N, Kazlauskas A, Ramesh V: A NHERF binding site links the betaPDGFR to the cytoskeleton and regulates cell spreading and migration. J Cell Sci 2004;117:2951-2961.

34 Negash S, Narasimhan SR, Zhou W, Liu J, Wei FL, Tian J, Raj JU: Role of cGMP-dependent protein kinase in regulation of pulmonary vascular smooth muscle cell adhesion and migration: effect of hypoxia. Am J Physiol Heart Circ Physiol 2009;297:H304-H312.

35 Stenmark KR, Fagan KA, Frid MG: Hypoxiainduced pulmonary vascular remodeling: cellular and molecular mechanisms. Circ Res 2006;99:675-691.

36 Tuder RM, Groves B, Badesch DB, Voelkel NF: Exuberant endothelial cell growth and elements of inflammation are present in plexiform lesions of pulmonary hypertension. Am J Pathol 1994;144:275-285.

37 Cool CD, Stewart JS, Werahera P, Miller GJ, Williams RL, Voelkel NF, Tuder RM: Threedimensional reconstruction of pulmonary arteries in plexiform pulmonary hypertension using cell-specific markers. Evidence for a dynamic and heterogeneous process of pulmonary endothelial cell growth. Am J Pathol 1999;155:411-419.

38 Hirose S, Hosoda Y, Furuya S, Otsuki T, Ikeda E: Expression of vascular endothelial growth factor and its receptors correlates closely with formation of the plexiform lesion in human pulmonary hypertension. Pathol Int 2000;50:472-479.

39 Sakao S, Tatsumi K, Voelkel NF: Endothelial cells and pulmonary arterial hypertension: apoptosis, proliferation, interaction and transdifferentiation. Respir Res 2009;10:95.

40 Taraseviciene-Stewart L, Kasahara Y, Alger L, Hirth P, Mc Mahon G, Waltenberger J, Voelkel NF, Tuder RM: Inhibition of the VEGF receptor 2 combined with chronic hypoxia causes cell death-dependent pulmonary endothelial cell proliferation and severe pulmonary hypertension. FASEB J 2001;15: 427-438.
41 Moreno-Vinasco L, Gomberg-Maitland M, Maitland ML, Desai AA, Singleton PA, Sammani S, Sam L, Liu Y, Husain AN, Lang RM, Ratain MJ, Lussier YA, Garcia JG: Genomic assessment of a multikinase inhibitor, sorafenib, in a rodent model of pulmonary hypertension. Physiol Genomics 2008;33: 278-291.

42 Teng RJ, Eis A, Bakhutashvili I, Arul N, Konduri GG: Increased superoxide production contributes to the impaired angiogenesis of fetal pulmonary arteries with in utero pulmonary hypertension. Am J Physiol Lung Cell Mol Physiol 2009;297:L184-L195.

43 Masri FA, Xu W, Comhair SA, Asosingh K, Koo M, Vasanji A, Drazba J, Anand-Apte B, Erzurum SC: Hyperproliferative apoptosisresistant endothelial cells in idiopathic pulmonary arterial hypertension. Am J Physiol Lung Cell Mol Physiol 2007;293:L548-L554.

44 Fantozzi I, Zhang S, Platoshyn O, Remillard CV, Cowling RT, Yuan JX: Hypoxia increases AP-1 binding activity by enhancing capacitative $\mathrm{Ca}^{2+}$ entry in human pulmonary artery endothelial cells. Am J Physiol Lung Cell Mol Physiol 2003;285:L1233-L1245.

45 Solodushko V, Parker JC, Fouty B: Pulmonary microvascular endothelial cells form a tighter monolayer when grown in chronic hypoxia. Am J Respir Cell Mol Biol 2008;38: 491-497.

46 Aldonytė R, Pivoriūnas A, Zhang J, Brantly M: Human neutrophil peptide 2 impairs wound-induced migration of cultured pulmonary artery endothelial cells. Act Medi Lituanic 2008;15:206-210.

47 Gorshkova I, He D, Berdyshev E, Usatuyk P, Burns M, Kalari S, Zhao Y, Pendyala S, Garcia JG, Pyne NJ, Brindley DN, Natarajan V: Protein kinase $\mathrm{C}$-epsilon regulates sphingosine 1-phosphate-mediated migration of human lung endothelial cells through activation of phospholipase D2, protein kinase Czeta, and Racl. J Biol Chem 2008;283: 11794-11806.

48 Phillips PG, Birnby LM, Narendran A: Hypoxia induces capillary network formation in cultured bovine pulmonary microvessel endothelial cells. Am J Physiol 1995;268: L789-L800. 